\title{
PENINGKATAN DOMAIN KOGNITIF, AFEKTIF DAN PSIKOMOTOR DALAM PROGRAM PEMBELAJARAN DI LUAR KAMPUS PADA MAHASISWA FAKULTAS ILMU KESEHATAN UNIVERSITAS MUHAMMADIYAH LAMONGAN
}

\section{(IMPROVEMENT COGNITIVE, AFFECTIVE AND PSYCHOMOTOR DOMAINS IN OFF-CAMPUS LEARNING PROGRAMS FOR STUDENTS OF THE FACULTY OF HEALTH SCIENCES, UNIVERSITAS MUHAMMADIYAH LAMONGAN)}

\footnotetext{
Virgianti Nur Faridah ${ }^{1}$, Arifal Aris ${ }^{2}$, Siti Sholikhah ${ }^{3}$, Dian Nurafifah ${ }^{4}$, Riana Prastiwi $^{5}$

1,2,3Prodi S1 Keperawatan, Fakultas Ilmu Kesehatan, Universitas Muhammadiyah Lamongan ${ }^{4}$ Prodi S1 Farmasi, Fakultas Ilmu Kesehatan, Universitas Muhammadiyah Lamongan

${ }^{5}$ Prodi D3 Farmasi, Fakultas Ilmu Kesehatan, Universitas Muhammadiyah Lamongan
}

\begin{abstract}
ABSTRAK
Latar Belakang : Perguruan tinggi bidang kesehatan pada dasarnya telah menerapkan merdeka belajar terutama pembelajaran di luar kampus jauh sebelum kebijakan Kampus Merdeka ini diluncurkan namun masih sebatas satu program kegiatan yaitu magang/praktek kerja. Ini merupakan tantangan bagi program studi kesehatan untuk dapat merancang dan melaksanakan proses pembelajaran di luar kampus yang inovatif pada delapan kegiatan dengan tetap memperhatikan capaian pembelajaran mencakup domain sikap, pengetahuan, dan keterampilan secara optimal. Penelitian ini bertujuan untuk melihat capaian pembelajaran mencakup domain kognitif, afektif dan psikomotor selama melakukan kegiatan belajar di luar kampus yang dilaksanakan program studi di Fakultas Ilmu Kesehatan Universitas Muhammadiyah Lamongan.

Metode : Penelitian ini menggunakan metode survey dengan menyebarkan angket kepada seluruh mahasiswa FIKES UMLA. sebanyak 960 mahasiswa (total sampling) yang terdiri dari 683 mahasiswa S1 Keperawatan, 95 mahasiswa S1 Administrasi Rumah Sakit dan 182 mahasiswa S1 Farmasi. Penelitian survei ini menggunakan teknik analisis data kuantitatif dengan pendekatan deskriptif.

Hasil : Hasil penelitian didapatkan dari domain kognitif sebesar 96,15\% menyatakan terjadi peningkatan saat dilakukan pembelajaran di luar kampus, domain afektif sebesar $96,15 \%$ dan domain psikomotor sebesar 95,83\%.

Kesimpulan : Program pembelajaran luar kampus mampu meningkatkan capaian pembelajaran mencakup domain kognitif, afektif dan psikomotor.
\end{abstract}

Kata Kunci : pembelajaran luar kampus, kognitif, afektif, psikomotor 


\section{ABSTRACT}

Background : Universities in the health sector have basically implemented independent learning, especially off-campus learning long before the "Kampus Merdeka" policy was launched, but it is still limited to one program of activities, namely internships/work practices. This is a challenge for the health study program to be able to design and implement an innovative off-campus learning process in eight activities while still paying attention to learning outcomes covering the domains of attitudes, knowledge, and skills optimally. This study aims to see learning outcomes covering cognitive, affective and psychomotor domains during off-campus learning activities carried out by study programs at the Faculty of Health Sciences, University Muhammadiyah Lamongan.

Method : This study uses a survey method by distributing questionnaires to all FIKES UMLA students. as many as 960 students (total sampling) consisting of 683 undergraduate students in Nursing, 95 undergraduate students in Hospital Administration and 182 undergraduate students in Pharmacy. This survey research uses quantitative data analysis techniques with a descriptive approach.

Results : The results obtained from the cognitive domain of $96.15 \%$ stated that there was an increase when learning was carried out outside the campus, the affective domain was $96.15 \%$ and the psychomotor domain was $95.83 \%$.

Conclusion : Off-campus learning programs are able to improve learning outcomes covering cognitive, affective and psychomotor domains.

Keyword: Off-campus learning, cognitive, affective, psychomotor

\begin{tabular}{ll}
\hline Alamat Korespondensi & $:$ Universitas Muhammadiyah Lamongan \\
Email & : virgianti_nf@yahoo.com \\
\hline
\end{tabular}

\section{PENDAHULUAN}

Dalam rangka menyiapkan mahasiswa menghadapi perubahan sosial, budaya, dunia kerja dan kemajuan teknologi yang pesat, kompetensi mahasiswa harus disiapkan untuk lebih gayut dengan kebutuhan zaman. Perguruan Tinggi dituntut untuk dapat merancang dan melaksanakan proses pembelajaran yang inovatif agar mahasiswa dapat meraih capaian pembelajaran mencakup aspek sikap, pengetahuan, dan keterampilan secara optimal dan selalu relevan. Kebijakan Merdeka Belajar - Kampus Merdeka diharapkan dapat menjadi jawaban atas tuntutan tersebut. Kampus Merdeka merupakan wujud pembelajaran di perguruan tinggi yang otonom dan fleksibel sehingga tercipta kultur belajar yang inovatif, tidak mengekang, dan sesuai dengan kebutuhan mahasiswa (Kemendikbud, 2020). Merdeka Belajar - Kampus Merdeka merupakan program kebijakan baru Kementerian Pendidikan dan Kebudayaan (Kemdikbud) Republik Indonesia dan diresmikan oleh Menteri Pendidikan dan Kebudayaan (Mendikbud), Nadiem Anwar Makarim. Kampus Merdeka akhir-akhir ini menjadi pusat perhatian kalangan pendidikan di Indonesia. Sejak diluncurkan sudah mampu menghipnotis seluruh civitas pendidikan di Indonesia. Kampus Merdeka diyakini sebagai upaya untuk membebaskan sistem pendidikan yang lebih mendukung mahasiswa dan dosen, dalam mewujudkan kualitas pembelajaran yang bermakna untuk menghadapi disrupsi era saat ini (Prahani et al., 2020). 
Kebijakan Merdeka Belajar - Kampus Merdeka (MBKM) juga diterapkan bagi perguruan tinggi di bidang kesehatan. Pada dasarnya, program studi kesehatan telah menerapkan merdeka belajar terutama pembelajaran di luar kampus jauh sebelum kebijakan MBKM ini diluncurkan. Namun masih sebatas satu program kegiatan di luar kampus yaitu magang/praktek kerja di Rumah Sakit. Ini merupakan tantangan bagi program studi kesehatan untuk dapat merancang dan melaksanakan proses pembelajaran di luar kampus yang inovatif pada delapan kegiatan dengan tetap memperhatikan capaian pembelajaran mencakup domain sikap, pengetahuan, dan keterampilan secara optimal. Berbagai pro dan kontra mewarnai peluncuran kebijakan ini yang akhirnya menjadi bahan pertimbangan bagi perguruan tinggi. Di satu sisi memandang bahwa relevansi materi pembelajaran yang selama ini dipelajari mahasiswa di kelas dengan kebutuhan dunia industri dan lapangan masih relatif rendah. Program ini juga dipandang mampu membekali mahasiswa dengan pengalaman baru serta membuka lebih lebar cakrawala pengetahuan dan pengalaman mahasiswa. Adapun pihak yang lain, beranggapan bahwa kebijakan ini akan berdampak; (1) kampus akan menjadi lahan kapitalisasi dan komersialisasi, (2) membuka perusahaan menyewa tenaga dengan upah (Kemendikbud, 2020)murah melalui pemanfaatan mahasiswa magang, (3) kesulitan dalam hal administrasi, (4) spesifikasi keilmuan menjadi tidak terlihat, dan (5) mahasiswa tidak bisa bebas memilih mata kuliah karena mereka harus memahami pengantar mata kuliah yang diambil (Muslim, 2020; Priatmoko \& Dzakiyyah, 2020).

Proses pembelajaran dalam Kampus Merdeka merupakan salah satu perwujudan pembelajaran yang berpusat pada mahasiswa (student centered learning) yang sangat esensial (Kemendikbud, 2020). Tujuan MBKM adalah untuk meningkatkan komptensi lulusan, baik soft skills maupun hard skills agar lebih siap dan relevan dengan kebutuhan zaman, menyiapkan lulusan sebagai pemimpin masa depan bangsa yang unggul dan berkepribadian. Bentuk kegiatan pembelajaran mengacu pada Permendikbud No. 3 Tahun 2020 Pasal 15 Ayat 1 dinyatakan dapat dilakukan di dalam delapan bentuk program yang meliputi: 1) pertukaran pelajar, 2) magang/praktik kerja, 3) mengajar di instansi pendidikan, 4) proyek di desa, 5) penelitian/riset, 6) kegiatan kewirausahaan, 7) studi/proyek independent dan 8) proyek kemanusiaan (Fuadi \& Aswita, 2021). Berbagai bentuk kegiatan merdeka belajar tersebut tetap akan dinilai capaian pembelajaran mahasiswa yang ditandai dengan perubahan tingkah laku secara keseluruhan yang meliputi aspek kognitif, afektif dan psikomotor (Nurtanto \& Sofyan, 2015). Peranan kognitif, afektif dan psikomotor dalam metode pembelajaran yang lama, pengukuran pencapaian materi pengajaran hanya ditekankan pada hasil, dan hanya pada aspek kognitif sering mengabaikan aspek lainnya. Sehingga kerap kali hasilnya tidak efektif, karena yang diperlukan justru sebuah proses dengan memperhatikan aspek afektif dan psikomotor. Sebelum sampai pada aspek psikomotor, terlebih dulu akan mengalami tahap kognitif dan afektif. Penelitian ini bertujuan untuk menganalisis capaian pembelajaran mencakup domain kognitif, afektif dan psikomotor selama melakukan kegiatan belajar di luar kampus yang dilaksanakan program studi di Fakultas Ilmu Kesehatan Universitas Muhammadiyah Lamongan (FIKES UMLA). Kampus merdeka diharapkan dapat memberikan pengalaman kontekstual lapangan yang akan meningkatkan kompetensi mahasiswa secara utuh, siap kerja, memberikan tantangan dan kesempatan untuk pengembangan inovasi, kreativitas, kapasitas, kepribadian, kemandirian dan manajemen diri. Melalui program merdeka 
belajar yang dirancang dan diimplementasikan dengan baik, maka hard dan soft skills mahasiswa akan terbentuk dengan kuat.

\section{METODE PENELITIAN}

Penelitian ini dilaksanakan menggunakan metode survey dengan menyebarkan angket kepada seluruh mahasiswa Fakultas Ilmu Kesehatan Universitas Muhammadiyah Lamongan (FIKES UMLA) di jenjang sarjana yaitu program studi S1 Keperawatan, S1 Farmasi dan S1 Administrasi Rumah Sakit tentang capaian pembelajaran mencakup domain kognitif, afektif dan psikomotor selama melakukan kegiatan belajar di luar kampus. Metode sampling yang dilakukan yaitu total sampling yang berjumlah 960 mahasiswa Fakultas Ilmu Kesehatan universitas Muhammadiyah Lamongan dengan rincian 683 mahasiswa S1 Keperawatan, 95 mahasiswa S1 Administrasi Rumah Sakit dan 182 mahasiswa S1 Farmasi. Data juga didapatkan dari wawancara kepada narasumber dan mitra tempat belajar di luar kampus yang terdiri dari 10 mitra dalam kota Lamongan yaitu Rumah Sakit, desa/komunitas dan apotek; serta 5 mitra luar kota Lamongan seperti Rumah Sakit dan Perguruan Tinggi mitra. Wawancara dilakukan kepada pembimbing mitra tempat belajar di luar kampus terkait hasil observasi capaian domain kognitif, afektif dan psikomotor. Data selanjutnya dianalisis sehingga didapatkan pengaruh program pembelajaran diluar kampus terhadap domain kognitif, afektif dan psikomotor mahasiswa Fakultas Ilmu Kesehatan Universitas Muhammadiyah Lamongan. Penelitian survei ini menggunakan teknik analisis data kuantitatif dengan pendekatan deskriptif.

\section{HASIL DAN DISKUSI}

\section{Hasil Penelitian}

Berdasarkan hasil penelitian yang sudah dilakukan pada 960 mahasiswa Fakultas Ilmu Kesehatan universitas Muhammadiyah Lamongan dengan rincian 683 mahasiswa S1 Keperawatan, 95 mahasiswa S1 Administrasi Rumah Sakit dan 182 mahasiswa S1 Farmasi, sebagian besar menyatakan bahwa pembelajaran di luar kampus meningkatkan domain kognitif, afektif dan psikomotor mahasiswa. Pembelajaran di luar kampus yang dimaksud seperti praktik kerja lapangan atau magang di Rumah Sakit, proyek di desa/komunitas, pertukaran pelajar serta online course. Hasil yang didapatkan dari domain kognitif sebesar 96,15\% menyatakan terjadi peningkatan saat dilakukan pembelajaran di luar kampus, domain afektif sebesar 96,15\% dan domain psikomotor sebesar 95,83\%. Hasil dapat dilihat pada tabel 1-6.

Tabel 1.

Hasil Terhadap Perubahan Kognitif

\begin{tabular}{lcc}
\hline $\begin{array}{l}\text { Perubahan } \\
\text { kognitif }\end{array}$ & $\begin{array}{c}\text { Jumlah } \\
\text { (responden) }\end{array}$ & $\begin{array}{c}\text { Persentase } \\
(\%)\end{array}$ \\
\hline Tetap & 37 & 3.85 \\
\hline $\begin{array}{l}\text { Terjadi } \\
\text { peningkatan }\end{array}$ & 923 & 96.15 \\
\hline Total & 960 & 100 \\
\hline
\end{tabular}


Tabel 2.

Hasil Terhadap Perubahan Afektif

\begin{tabular}{lcc}
\hline Perubahan afektif & $\begin{array}{c}\text { Jumlah } \\
\text { (responden) }\end{array}$ & Persentase (\%) \\
\hline Tetap & 37 & 3.85 \\
\hline $\begin{array}{l}\text { Terjadi } \\
\text { peningkatan }\end{array}$ & 923 & 96.15 \\
Total & 960 & 100.00 \\
\hline
\end{tabular}

Tabel 3.

Hasil Terhadap Perubahan Psikomotor

\begin{tabular}{lcc}
\hline Perubahan psikomotor & $\begin{array}{c}\text { Jumlah } \\
\text { (responden) }\end{array}$ & $\begin{array}{c}\text { Persentase } \\
(\%)\end{array}$ \\
\hline Tetap & 40 & 4.17 \\
\hline Terjadi peningkatan & 920 & 95.83 \\
\hline Total & 960 & 100.00 \\
\hline
\end{tabular}

Tabel 4.

Kebermanfaatan MBKM terhadap domain kognitif

\begin{tabular}{lcc}
\hline $\begin{array}{l}\text { Manfaat MBKM terhadap } \\
\text { kognitif }\end{array}$ & $\begin{array}{c}\text { Jumlah } \\
\text { (responden) }\end{array}$ & $\begin{array}{c}\text { Persentase } \\
(\%)\end{array}$ \\
\hline Cukup bermanfaat & 496 & 51.67 \\
\hline Sangat bermanfaat & 464 & 48.33 \\
\hline Total & 960 & 100 \\
\hline
\end{tabular}

Tabel 5.

Kebermanfaatan MBKM terhadap domain afektif

\begin{tabular}{lrr}
\hline Manfaat MBKM terhadap afektif & $\begin{array}{c}\text { Jumlah } \\
\text { (responden) }\end{array}$ & \multicolumn{2}{c}{ Persentase (\%) } \\
\hline Cukup bermanfaat & 496 & 51.67 \\
\hline Sangat bermanfaat & 464 & 48.33 \\
\hline Total & 960 & 100 \\
\hline
\end{tabular}

Tabel 6.

Kebermanfaatan MBKM terhadap domain psikomotor

\begin{tabular}{lcc}
\hline Manfaat MBKM terhadap psikomotor & $\begin{array}{c}\text { Jumlah } \\
\text { (responden) }\end{array}$ & $\begin{array}{c}\text { Persentase } \\
(\%)\end{array}$ \\
\hline cukup bermanfaat & 166 & 17.29 \\
\hline sangat bermanfaat & 794 & $\mathbf{8 2 . 7 1}$ \\
\hline Total & 960 & 100.00 \\
\hline
\end{tabular}


Peneliti juga melakukan wawancara dengan pembimbing dari 15 mitra tempat belajar di luar kampus. Berdasarkan hasil wawancara, didapatkan bahwa 90\% mitra menyatakan puas dengan kemampuan kognitif mahasiswa saat dilakukan responsi. Pembimbing mitra menyatakan bahwa mahasiswa mampu mendeskripsikan teori, menyimpulkan, membahas dan memecahkan suatu kasus serta membuat laporan dalam kegiatan Student Oral Case Analysis (SOCA). Pada domain afektif/sikap, didapatkan bahwa $80 \%$ pembimbing mitra menyatakan cukup puas dengan kemampuan afektif mahasiswa selama melakukan pembelajaran diluar kampus. Pembimbing mitra menyatakan bahwa sebagian besar mahasiswa mampu menunjukkan atensi atau penghargaan terhadap orang lain, mentaati aturan dan disiplin. Sedangkan pada domain psikomotor, didapatkan bahwa 95\% pembimbing mitra menyatakan puas dengan kemampuan psikomotor mahasiswa saat dilakukan kegiatan Direct Observasional of Procedural Skill (DOPS). Pembimbing mitra menyatakan bahwa sebagian besar mahasiswa mampu melakukan suatu ketrampilan/tindakan dengan baik meskipun masih dalam pantauan pembimbing mitra.

Hasil penelitian tersebut menunjukkan bahwa kegiatan pembelajaran di luar kampus sangat bermanfaat bagi mahasiswa karena dengan begitu, mahasiswa lebih mudah memahami materi-materi yang sudah disampaikan saat pembelajaran di kampus, baik materi akademik maupun non akademik, mendapatkan pengalaman baru terkait kegiatan di luar kampus yang sesuai dengan passion mahasiswa dan mengasah softskills mahasiswa saat berada di lapangan sebagai bekal untuk bekerja setelah lulus nanti serta mengasah kemampuan berpikir kritis mahasiswa untuk menyelesaikan problematika yang ada di lapangan atau masyarakat.

\section{Diskusi Hasil}

\section{Kegiatan Pembelajaran Di Luar Kampus}

Ada dua konsep yang esensial dalam "Merdeka Belajar" dan "Kampus Merdeka". Pertama, konsep merdeka belajar mengandung arti adanya kemerdekaan berpikir. Menurut Nadiem Makarim bahwa esensi kemerdekaan berpikir harus dimulai terlebih dulu oleh para pendidik. Pandangan seperti ini harus dilihat sebagai suatu upaya untuk menghormati perubahan dalam pembelajaran di lembaga Pendidikan baik di sekolah dasar, menengah maupun perguruan tinggi. Kedua, kampus merdeka merupakan kelanjutan dari konsep merdeka belajar. Kampus merdeka merupakan upaya untuk melepaskan belenggu untuk bisa bergerak lebih mudah (Nora Susilawati, 2021). Bentuk kegiatan di luar perguruan tinggi dapat berupa magang atau praktik kerja, melaksanakan proyek pengabdian kepada masyarakat di desa, mengajar di satuan pendidikan, mengikuti pertukaran mahasiswa, melakukan penelitian, melakukan kegiatan kewirausahaan, membuat studi atau proyek independen, dan mengikuti program kemanusiaan (Prahani et al., 2020). Sebenarnya, semua kegiatan tersebut bisa diterapkan pada program studi kesehatan, namun yang telah diterapkan dalam penelitian ini adalah magang atau praktik kerja, melaksanakan proyek pengabdian kepada masyarakat di desa, dan mengikuti pertukaran mahasiswa.

a) Magang/praktik kerja, mahasiswa kesehatan dapat mengikuti magang di

Rumah Sakit baik milik pemerintah maupun swasta, Selama magang, 
mahasiswa harus diawasi oleh dosen atau pengawas. Tujuannya agar teori di kampus bisa diterapkan saat magang.

b) Proyek di desa, serupa dengan Program Pengabdian kepada Masyarakat. Dalam hal ini mahasiswa kesehatan akan terlibat dalam kegiatan praktek di komunitas/desa. Proyek sosial ini untuk membantu orang-orang di pedesaan atau daerah terpencil membangun ekonomi kerakyatan, memandirikan masyarakat untuk menemukan dan memecahkan masalah kesehatan masyarakatnya sendiri, meningkatkan taraf kesehatan masyarakat, dan lainnya. Kegiatan ini dapat dilakukan berkolaborasi dengan perangkat desa (kepala desa), bidan dan perawat desa

c) Pertukaran mahasiswa, merupakan salah satu kegiatan di luar kampus yang banyak diminati mahasiswa. Dalam hal ini, mahasiswa kesehatan bisa mengambil kelas atau mata kuliah di universitas luar negeri atau dalam negeri. Pelaksanaannya bisa berupa online course dan hybrid learning. Dengan demikian, mahasiswa dapat memperoleh tambahan pengetahuan dan suasana baru dikampus lain. Nilai dan kredit yang diambil di perguruan tinggi di luar akan menjadi disinkronkan oleh masing-masing perguruan tinggi.

\section{Capaian domain kognitif, afektif dan psikomotor}

Hasil yang didapatkan dari domain kognitif sebesar 96,15\% menyatakan terjadi peningkatan saat dilakukan pembelajaran di luar kampus, domain afektif sebesar 96,15\% dan domain psikomotor sebesar 95,83\%. Kebermanfaatan MBKM terhadap domain kognitif didapatkan cukup bermanfaat sebesar 51,67\%, domain afektif juga didapatkan cukup bermanfaat sebesar 51,67\% dan domain psikomotor didapatkan sangat bermanfaat sebesar 82,71\%. Terajadinya peningkatan domain kognitif, afektif dan psikomotor disebabkan karena mahasiswa lebih mudah memahami materi yang sudah disampaikan saat pembelajaran di dalam kampus, baik materi akademik maupun non akademik, mendapatkan pengalaman baru terkait kegiatan di luar kampus yang sesuai dengan passion mahasiswa dan mengasah softskills mahasiswa saat berada di lapangan sebagai bekal untuk bekerja setelah lulus nanti serta mengasah kemampuan berpikir kritis mahasiswa untuk menyelesaikan problematika yang ada di lapangan atau masyarakat. Hal ini lebih melengkapi proses pembelajaran di dalam kampus, dimana pengukuran pencapaian materi pengajaran hanya ditekankan pada hasil bukan proses, dan lebih banyak pada aspek kognitif sering mengabaikan aspek lainnya.

Hasil penelitian tersebut sejalan dengan penelitian yang dilakukan di Institut Agama Kristen Negeri (IAKN) Kupang, bahwa penerapannya mampu meningkatkan kemampuan kognitif mahasiswa secara baik dan mampu berrinovasi dengan baik melalui berbagai cara yang digunakan seperti menemukan ide-ide baru dalam proses pembelajaran (Lao \& Hendrik, 2020). Berbagai bentuk kegiatan merdeka belajar tersebut tetap akan dinilai pencapaian hasil belajar mahasiswa. Hasil belajar merupakan kemampuan-kemampuan yang dimiliki peserta didik setelah mengikuti pembelajaran. UNESCO 
mengemukakan bahwa hasil belajar yang akan dicapai terdiri atas empat pilar, diantaranya: (1) learning to know (belajar mengetahui); (2) learning to do (belajar melakukan sesuatu); (3) learning to be (belajar menjadi sesuatu); dan (4) learning to live together (belajar hidup bersama). Hasil belajar ditandai dengan perubahan tingkah laku secara keseluruhan yang meliputi aspek kognitif, afektif dan psikomotor. Proses perubahan dapat terjadi dari yang paling sederhana sampai yang paling kompleks. Bloom membagi "learning domain" sebagai tujuan dirumuskan kedalam tiga klasifikasi atau aspek yaitu: (1) aspek cognitive; (2) aspek affective; dan (3) aspek psychomotor. Ranah kognitif Bloom dibagi menjadi 6 tingkatan yaitu pengetahuan (knowledge), pemahaman (comprehension), penerapan (application), analisis (analysis), sintesis (synthesis), dan evaluasi (evaluaton). Ranah afektif meliputi menerima (recaiving), merespons (responding), menghargai (valuating), mengatur (organizing), dan berkarakter (characterization). Ranah psikomotor meliputi imitasi (imitation), manipulasi (manipulation), presisi (precision), artikulasi (articulation), dan naturalisasi (naturalization) (Nurtanto \& Sofyan, 2015).

Kampus merdeka merupakan perpanjangan dari program merdeka belajar yang memberikan mahasiswa kebebasan untuk tiga semester mencari pengalaman belajar diluar kampus (Kemendikbud, 2020). Perguruan tinggi diharapkan mampu melakukan inovasi-inovasi dalam setiap proses pembelajarannya yakni pembelajaran yang berpusat pada mahasiswa agar mendukung tercapainya lulusan yang berkualitas yang siap menghadapi situasi zaman yang terus berubah. Mahasiswa tidak hanya menjadi lulusan terbaik yang pandai dalam berteori akan tetapi mampu merealisasikan teori. Terjun ke lapangan dengan bekal ilmu yang dalam untuk terobosan yang relevan demi kemajuan pendidikan yang tidak pernah berkesudahan (Siregar, Sahirah, \& Harahap, 2020). Perguruan tinggi harus melakukan langkah-langkah penyesuaian terhadap pelaksanaan tri darma perguruan tinggi, baik menyangkut kegiatan akademik maupun non akademik, termasuk dalm hal penyesuian anggaran pendidikan tiap tahun akademik (Muslikh, 2020). Terlepas dari itu semua, kebijakan ini juga memiliki potensi kelemahannya, yaitu banyaknya studi yang diambil dapat mengganggu arah jalur studi dan perubahan kebijakan oleh setiap menteri kurang memperhatikan aspek keberlanjutan (Lhutfi \& Mardiani, 2020).

\section{SIMPULAN DAN SARAN}

Program pembelajaran luar kampus mampu meningkatkan capaian pembelajaran mencakup domain kognitif, afektif dan psikomotor pada mahasiswa kesehatan. Penelitian lanjutan diharapkan lebih detail dalam menganalisis peningkatan domain kognitif, afektif dan psikomotor dan dapat memaparkan hambatan yang dialami oleh perguruan tinggi kesehatan. Keterbatasan penelitian ini adalah belum mencakup penilaian kognitif, afektif dan psikomotor dari pihak dosen dan dari hasil belajar mahasiswa. 


\section{UCAPAN TERIMA KASIH}

Atas publikasi ini penulis mengucapkan terima kasih kepada ditjen dikti ristek atas bantuan pendanaan program penelitian Kebijakan Merdeka Belajar Kampus Merdeka dan Pengabdian kepada Masyarakat Berbasis Hasil Penelitian dan Purwarupa PTS Tahun Anggaran 2021.

\section{DAFTAR PUSTAKA}

Fuadi, T. M., \& Aswita, D. (2021). Merdeka Belajar Kampus Merdeka (Mbkm): Bagaimana Penerapan Dan Kedala Yang Dihadapi Oleh Perguruan Tinggi Swasta Di Aceh. Jurnal Dedikasi Pendidikan, 5(2), 603-614. Retrieved from http://jurnal.abulyatama.ac.id/index.php/dedikasi

Kemendikbud, R. D. J. P. T. (2020). Buku Panduan Merdeka Belajar - Kampus Merdeka. https://doi.org/10.31219/osf.io/ujmte

Lao, H. A., \& Hendrik, Y. Y. (2020). Implementasi kebijakan kemerdekaan belajar dalam proses pembelajaran di Kampus IAKN Kupang-NTT. Dedikasi Pendidikan, 4(2), 201-210. Retrieved from http://jurnal.abulyatama.ac.id/index.php/dedikasi

Lhutfi, I., \& Mardiani, R. (2020). Merdeka Belajar - Kampus Merdeka Policy: How Does It Affect the Sustainability on Accounting Education in Indonesia? Dinamika Pendidikan, 15(2), 243-253. https://doi.org/10.15294/dp.v15i2.26071

Muslikh. (2020). Landasan Filosofis dan Analisis Terhadap Kebijakan Merdeka Belajar Dan Kampus Merdeka. Jurnal Syntax Transformation, 1(3), 40-46.

Muslim, S. A. M. (2020). Tantangan Implementasi Kebijakan "Merdeka Belajar, Kampus Merdeka” pada Perguruan Tinggi Islam Swasta di Indonesia. 1-11.

Nora Susilawati. (2021). Merdeka Belajar dan Kampus Merdeka Dalam Pandangan Filsafat Pendidikan Humanisme Nora Susilawati Universitas Negeri Padang Email : norasusilawati1973@gmail.com. Jurnal Sikola:Jurnal Kaajian Pendidikan Dan Pembelajaran, 2(3), 203-219.

Nurtanto, M., \& Sofyan, H. (2015). Implementasi Problem-Based Learning Untuk Meningkatkan Hasil Belajar Kognitif, Psikomotor, the Implementation of Problem-Based Learning To Improve Learning Outcomes of Cognitive , Psychomotor, and Affective of Students in. Jurnal Pendidikan Vokasi, 5(November 2015), 352-364.

Prahani, B. K., Utama Alan Deta, Mochammad Yasir, Sri Astutik, Paken Pandiangan, Sayidah Mahtari, \& Husni Mubarok. (2020). The Concept of "Kampus Merdeka" in Accordance with Freire's Critical Pedagogy. Studies in Philosophy of Science and Education, 1(1), 21-37. https://doi.org/10.46627/sipose.v1i1.8

Priatmoko, S., \& Dzakiyyah, N. I. (2020). Relevansi Kampus Merdeka Terhadap Kompetensi Guru Era 4.0 Dalam Perspektif Experiential Learning Theory. AtThullab: Jurnal Pendidikan Guru Madrasah Ibtidaiyah, 4(1), 1. https://doi.org/10.30736/atl.v4i1.120

Siregar, N., Sahirah, R., \& Harahap, A. A. (2020). Konsep Kampus Merdeka Belajar Di Era. Fitrah:Journal of Islamic Education, 1(1), 141-157. 